-ORIGINAL ARTICLE-

Volume 13 Issue 42021

DOI: 10.21315/eimj2021.13.4.7

ARTICLE INFO

Received: $31-03-2020$

Accepted: 10-08-2021

Online: 30-12-2021

\section{Development of Critical Thinking Transfer Practice Construct and Sub-Constructs: A 9-steps Approach}

\author{
Noor Azura Mat Said ${ }^{1,2}$, Siti Mariam Bujang2, Nor Aishah Buang ${ }^{3}$, \\ Mohd Nasri Awang Besar², Harlina Halizah Siraj @ Ramli² \\ ${ }^{1}$ Faculty of Medicine and Health Sciences, Universiti Sains Islam \\ Malaysia, Negeri Sembilan, MALAYSIA \\ ${ }^{2}$ Department of Medical Education, Faculty of Medicine, Universiti \\ Kebangsaan Malaysia, Selangor, MALAYSIA \\ ${ }^{3}$ Centre of STEM Enculturation, Faculty of Education, Universiti \\ Kebangsaan Malaysia, Selangor, MALAYSIA
}

To cite this article: Mat Said NA, Bujang SM, Buang NA, Awang Besar MN, Siraj @, Ramli HH. Development of critical thinking transfer practice construct and sub-constructs: a 9-steps approach. Education in Medicine Journal. 2021;13(4):85-101. https://doi.org/10.21315/eimj2021.13.4.7

To link to this article: https://doi.org/10.21315/eimj2021.13.4.7

\begin{abstract}
The study aimed to develop critical thinking transfer practice (CTTP) construct and sub-constructs relevant to medical undergraduates. The study used a 9-step qualitative case study approach. The prior relationship of construct and sub-constructs were conceptualised to produce the initial thematic framework (Step 1 to 3 ). Then, a qualitative study confirmed the sub-constructs that were relevant for the undergraduates, as the new data were fitted into the initial framework to become an evolving framework (Step 4 to 5). Next, the construct and sub-constructs were defined operationally (Step 6) and evaluated (Step 7). After that, the evolving framework was revised (Step 8) and developed to become the final construct and sub-constructs (Step 9). Based on the literature, the study conceptualised an initial framework that described the theoretical relationship of the prior construct and six sub-constructs. From the qualitative findings, 37 codes were fitted into the initial framework. The fitting resulted in an evolving framework that contained a theme (the medical undergraduates' CTTP), 6 categories and 26 sub-categories. A 100\% of participants agreed that the data were generated from them. Then, the team members and the expert panels accepted the theme (Cohen Kappa value $>0.80$ ). The maintained and revised theme, categories and sub-categories were used to develop the CTTP construct and 6 sub-constructs. The study discussed in detail the included subconstructs for CTTP. The study also addressed the similarities and differences of the construct and sub-constructs for medical education and general studies. The study concluded that the construct and sub-constructs were theoretically proven to represent the medical undergraduates' CTTP.
\end{abstract}

Keywords: Critical thinking transfer, Medical undergraduates, Content validity, Expert evaluation 


\section{INTRODUCTION}

The importance of critical thinking in the 21 st century is undeniable. Hence, numerous studies were conducted on critical thinking, especially related to critical thinking transfer (1-4). In medical education, critical thinking is regarded as an essential competency factor for medical undergraduates to work in the professional area. It is one of the aims and criteria in medical education for the medical schools to be accredited by professional bodies (5-7).

Most critical thinking theorists (8-10) agreed that medical education needs to develop a curriculum that helps the medical undergraduates not only master critical thinking but promotes the critical thinking transfer in solving everyday issues. In Malaysia, critical thinking transfer is a crucial skill that medical undergraduates should acquire. One justification is the educational transformation in medical education from a subject-based approach to the mixture of self-learning and blended learning, focusing on the human systembased approach (11-12). The educational transformation urges undergraduates to transfer their critical thinking skills. For example, transfer of analysis skill to compare a system with other systems, transfer the skill of information evaluation to be disseminated to various sources, or transfer the synthesis skill to build the connection between the systems to the human diseases and communities.

Another justification is that a multifaceted conceptualisation regarding critical thinking transfer concepts among the theorists (2, 13-14) may raise confusion among the medical undergraduates in understanding the concepts. The lack of understanding produces undergraduates with low-level critical thinking (15-16). Based on the literature (17), the understanding concept is the first thinking level before critical thinking transfer. Besides, studies of critical thinking constructs such as critical thinking skills and dispositions $(14,18-20)$, as well as learning transfer $(6,21-22)$ are conducted separately, which limits the connection between critical thinking and learning transfer.

The prior sub-constructs regarding critical thinking learning transfer are derived from the underlying theories $(4,10$, 22-44). Those prior sub-constructs are subconstruct A (different conceptualisations on critical thinking transfer concepts), sub-construct $\mathrm{B}$ (situations that allow the critical thinking transfer), sub-construct $\mathrm{C}$ (understanding and examining the deep structure of the problem), sub-construct D (rapid recognition of problem), subconstruct E (deliberate practice) and subconstruct $\mathrm{F}$ (learning strategies that promote critical thinking transfer). However, the prior sub-constructs were studied differently. Besides, studies related to the critical thinking transfer in Malaysia are still lacking compared to other countries (18-19, 23). Thus, this study adds to the available information on critical thinking transfer practice (CTTP) in the medical education context conducted in Malaysia.

The 6 prior sub-constructs $\mathrm{A}$ to $\mathrm{F}$ were adopted in this study. However, the construct and these sub-constructs were discussed separately and their relationship was not established in the literature. Another limitation was their applications were reported only for general learning $(4,6,18-19,22,24-28)$. To address these limitations, a study framework was conceptualised (Figure 1) that represented the relationship among the prior construct and sub-constructs of CTTP. Hence, this study aimed to develop the CTTP construct and sub-constructs relevant to medical undergraduates in Malaysia's public university. 


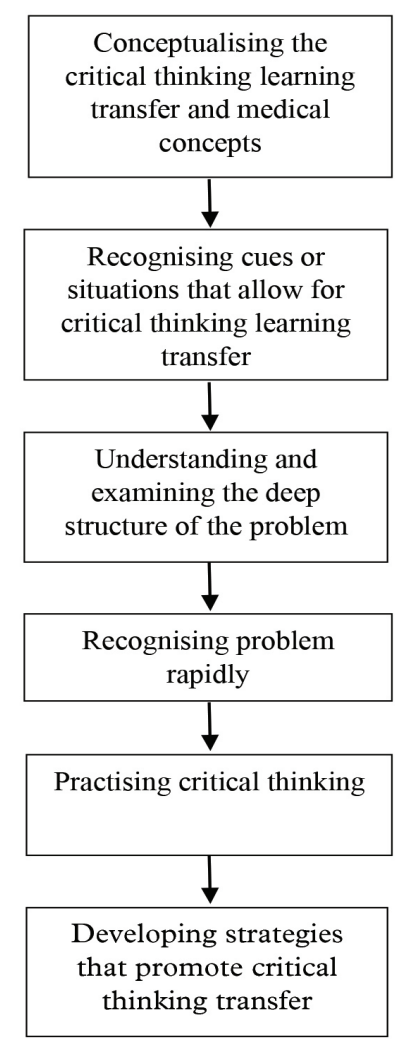

Figure 1: The study framework.

\section{METHODS}

\section{Research Design}

This study used a qualitative case study design as the study aimed to focus on the specific case. The population for the case study was the medical undergraduates that have participated a formal critical thinking training in Malaysia's public university. Also, the qualitative design was used to develop the specific final construct and subconstructs relevant for participants (the medical undergraduates) as recommended by Merriam and Tisdell (29).

\section{Selection and Description of Participants}

The participants were eight third-year medical undergraduates enrolled in the early clinical year programme in Malaysia's public university. As the study focused on the CTTP construct, the undergraduates were chosen because they have enrolled in formal critical thinking training during pre-clinical years under personal and professional development as well as problem-based learning modules. Then, in the subsequent clinical years, they have practised and applied critical thinking in different clinical and non-clinical situations. Besides, the undergraduates were selected due to their experiences related to critical thinking learning transfer still fresh in their mind to be researched in this study as stressed out by Sutton and Austin, "The experience that needs to be explored were still new in the participants' mind, whereas on other occasions reliving past experiences may be difficult" (30, p. 227). Based on the difficulty in retrieving past experiences, as Sutton and Austin stated, this study did not consider middle and final-year medical undergraduates.

The selection also focused on the CTTP, solely based on the medical curriculum of Universiti Kebangsaan Malaysia. Hence, middle and final-year medical undergraduates were excluded because their practices were primarily influenced by workplace-based learning as their learning process mainly occurred in the hospitals. The participants were selected using the snowball sampling method by approaching the head of the medical programme and obtaining the participants' background information to ensure their approachability and variation in the participants' perspectives. The sampling method used also allowed for the maximum variation in the backgrounds of the participants such as clinical postings, races and gender, as described in Table 1. 
Table 1: Participants' profile

\begin{tabular}{llll}
\hline Research participants & Gender & Residency & Clinical posting \\
\hline Participant 1 & Male & Non-residence & Clinical posting 1: Internal medicine \\
Participant 2 & Female & Residence & Clinical posting 2: Public health \\
Participant 3 & Male & Residence & Clinical posting 4: Obstetrics and gynaecology \\
Participant 4 & Female & Residence & Clinical posting 2: Public health \\
Participant 5 & Female & Non-residence & Clinical posting 4: Obstetrics and gynaecology \\
Participant 6 & Male & Non-residence & Clinical posting 3: Surgery \\
Participant 7 & Female & Residence & Clinical posting 3: Surgery \\
Participant 8 & Female & Residence & Clinical posting 3: Surgery \\
\hline
\end{tabular}

\section{Procedures}

Figure 2 shows the construct and subconstructs development process based on the 9-steps approach designed in this study.

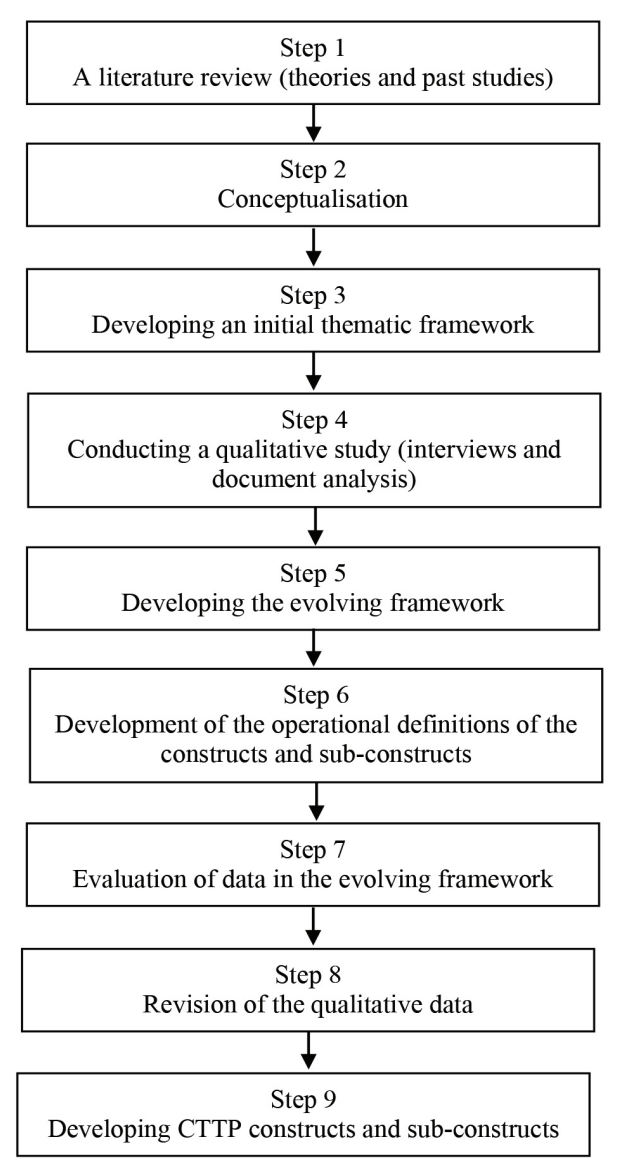

Figure 2: Process of CTTP construct and subconstructs development.

\section{Step 1: A literature review}

In Step 1, a combination of four theories and two models was used to conceptualise the CTTP prior to the development of the construct, sub-constructs and their relationship, as shown in Figure 1. Based on Figure 1, the CTTP always begins by understanding the concepts as emphasised by the cognitive processing model and cognitive load theory (31-32). The schema construction was previously explained by Khalil and Elkhider (33). Both theories were chosen because they described the importance of knowledge as a fundamental for critical thinking learning transfer. In the study context, the knowledge was referred to as the CTTP and medical concepts conceptualised as the sub-construct A. In understanding the CTTP concept, this study adopted the learning transfer theory (34) and the critical thinking transfer concept $(4,22,35)$.

Next, the cognitive schema theory (36-38) was chosen to describe how the external outputs from the learning environment fit the learners' thinking schema and form the schema arrangement. The schema arrangement leads to the automaticity in the learners' minds as described in the cognitive schema theory (36-38). Thus, the learners can adapt to different learning contents and take exact action towards the learning environment. The automaticity also relates to the recognition of cues or keywords that 
served as a signal for retrieving the related thinking schemas (39-40). Therefore, based on the cognitive schema theory, the subconstruct B was conceptualised in this study.

The cognitive schema theory also describes the cognitive schema arrangement to help the learner in making a prior evaluation of the clinical scenario. This evaluation leads the learners to the critical elements presented in the clinical problem, which required cognitive processing (41). Thus, the learners can recognise the deep structure of the problem, which includes the problem definition, the possible sign and symptoms, and the critical characteristics of the disease conceptualised as the sub-construct $\mathrm{C}$ of the study. In addition, the cognitive schema theory describes the evaluation of essential elements of a clinical problem that leads to the learner's ability to recognise the clinical problem quickly (42-44). Thus, the subconstruct $\mathrm{D}$ was conceptualised that allowed the ability of the participants to identify a problem rapidly.

Besides, cognitive load theory $(33,37)$ and the model of teaching critical thinking transfer across domains (10) have suggested that the learners need to train and practice critical thinking skills to trigger the thinking process. Also, this theory explained the correct selection of any learning activities that can enhance critical thinking. The proper selection of the learning activities would be the best solution to reduce the extraneous and germane loads so that thinking can occur. Based on the cognitive load theory, sub-construct E was conceptualised that the participants need to train and practice their critical thinking knowledge and skills in transferring critical thinking. A sub-construct $\mathrm{F}$ was conceptualised simultaneously as described by the cognitive processing model, in which the participants must adapt thinkingpromoted learning strategies to initiate the critical thinking learning transfer (33).

All the theories and models that contributed to the emergence of the prior CTTP construct and sub-constructs were explained clearly. However, those construct and subconstructs were not related to each other.

\section{Step 2: The researchers' conceptualisation of the relationship among CTTP constructs and sub- constructs}

In Step 2, the study has conceptualised a framework in Figure 1. The framework showed the theoretical relationship among the prior CTTP construct and subconstructs. The study used the framework in Figure 1 as a guide to develop qualitative data (the theme, categories, sub-categories, codes and the elements). The element referred to the participant's responses in the interview transcripts, while a combination of elements was known as the code was established. Next, the codes were combined to form a sub-category. A collection of the sub-categories formed the categories, and finally, the categories formed a theme.

\section{Step 3: Development of the initial thematic framework}

Before the qualitative data was interpreted, the study developed an initial thematic framework in Step 3 based on those prior CTTP construct and sub-constructs. The thematic framework described the mapping of the previous construct and sub-constructs based on the literature. This thematic framework guided the conduct of qualitative research as described in Step 4.

\section{Step 4: Conducted a qualitative study}

Next, qualitative study is conducted to confirm the established construct and sub-constructs in the context of medical undergraduates' learning. Step 4 used face-to-face interviews and document analysis. Based on the qualitative study, the participant's responses in the interview transcripts and the relevant documents were analysed using framework analysis. The analysis resulted in the emergence of qualitative data (elements, codes and subcategories). These data were fit under each established sub-construct and construct in 
the initial thematic framework. The fitting resulted in the sub-constructs formed the categories, while the construct formed the theme. The elements were labelled with R1TB1TSCTLine 1-3 (R1 = Participant number $1 ; \mathrm{TB} 1=$ Interview session 1 ; TSCT $=$ Label of category; Line $1-3=$ Line in the interview transcript).

\section{Step 5: Development of the evolving framework}

As aforementioned, the qualitative subcategories, codes and elements were fitted under the construct and sub-constructs in the initial thematic framework that formed the theme and categories, respectively. This fitting turned the initial thematic framework into the evolving framework. The framework described the mapping of the theme, categories, sub-categories, codes and elements towards the combination of sources (theories, past studies and qualitative data). Then, the study used the evolving framework to develop the final CTTP construct and sub-constructs. Those final construct and sub-constructs were relevant for medical undergraduates' learning.

\section{Step 6: Defining the themes, categories and codes}

Next, the operational definitions were given to the theme, categories and sub-categories derived from the literature and qualitative findings in Step 6. Operationalisation is a process of determining the constructs, providing meaning to construct, and describing how the construct is being measured, and transforming the complex content of the constructs into items that could be answered by the research participants (45-46).

After that, the developed operational definitions were mapped out together with the theme, categories and sub-categories in the evolving framework. The next step was to confirm the themes, categories, subcategories, codes and elements by the team members and expert panels. The codes were also approved by the study participants.

\section{Step 7: Confirmation of data in the evolving framework}

Then, qualitative codes and data were evaluated by three procedures. In the first procedure, the member checking procedure was conducted by giving the qualitative codes to the participants. The procedure confirmed that the codes were derived from the participants. This procedure was also conducted to ensure the researchers' interpretation of the data was parallel with the participants' views. The participants consented by signing on every page of the interview transcripts that have been labelled with the codes.

In the second procedure, peer review confirmed the definitions of the themes, categories, codes and operational based on the literature $(29,47)$. The purpose of the peer review was to ensure the theme, categories, codes and operational definitions were paralleled to the objective of the study. In the peer review, the team members compared the qualitative data and data from the literature in the initial thematic framework. This comparison confirmed the similarity between the data that emerged from literature and the data in the qualitative findings. The comparison was also looked for the emergence of the new data.

In the third procedure, the confirmation of the data was conducted through the expert panel evaluation. The expert panel evaluation determined the experts' degree of agreement on the data following the objective of the study. The experts consisted of a qualitative expert and a critical thinking expert, as suggested by the literature (48-49). The degree of agreement of the experts was determined using Cohen Kappa (50).

\section{Step 8: Revision of data in the evolving framework}

In Step 8, the study refined the data in the evolving framework. Some data were maintained, revised and removed. 


\section{Step 9: Development of CTTP construct and sub-constructs that relevant for medical undergraduates}

In the last step (Step 9), the maintained and revised data were used to develop the final CTTP construct, sub-constructs and attributes that are relevant for the medical undergraduates' learning. The theme formed the construct from the revision, categories formed the sub-constructs and sub-categories formed the attributes.

\section{RESULTS}

An initial thematic framework contained a theme (the CTTP of medical undergraduate), six categories (Categories A to $F$ ) determined based on the literature and none sub-categories. During the qualitative study, the new qualitative data were fitted into the initial thematic framework. The new data consisted of 37 qualitative codes (Table 2) from 16 interviews and 3 documents. The codes resulted in the emergence of 26 sub-categories that were relevant to medical undergraduates learning. The sub-categories were subsumed under the prior 6 sub-constructs to form a theme in the evolving framework. Then, the CTTP theme, categories, sub-categories and codes were given the operational definitions. Table 3 summarises the operational definitions adapted from both literature and qualitative findings.

Table 2: Codes from the qualitative study

\begin{tabular}{llll}
\hline No. & Codes & No. & Codes \\
\hline 1. & Intra-subject transfer & 20. & Recognition of unique elements/classical findings \\
2. & Inter-subject transfer & 21. & The complexity of a clinical problem \\
3. & Trans-discipline transfer & 22. & Existence of a specific keyword in a problem \\
4. & Transfer to entirely new situations & 23. & Existence of specific characteristics of a problem \\
5. & Integrated transfer & 24. & Recognised a clinical problem \\
6. & Learning situations & 25. & Understood the clinical problem \\
7. & Personal situations & 26. & Inquired the clinical problem \\
8. & Daily situations & 27. & Decided the clinical problem \\
9. & Non-learning situations & 28. & Aim of critical thinking practice \\
10. & Problem definition & 29. & Time for practicing critical thinking \\
11. & Etiology of diseases & 30. & Opportunities for practice and repeated critical thinking \\
12. & Signs and symptoms & 31. & Self-awareness on the importance of practice critical thinking \\
13. History of past diseases & 32. & Surface learning strategy \\
14. & Pathophysiological mechanism & 33. & Active learning strategy \\
15. & Psychosocial factor & 34. & Proactive learning strategy \\
16. & Clinical investigation & 35. & Classroom learning strategy \\
17. & Treatment/intervention & 36. & Experiential learning strategy \\
18. & Rapid recognition of a clinical problem & 37. & Procedural learning strategy \\
19. & Automatic recognition of a clinical problem & & \\
\hline
\end{tabular}


Table 3: Operational definitions for the themes and categories

\begin{tabular}{ll}
\hline Theme/category & $\begin{array}{l}\text { Operational definitions adapted from the literature and qualitative } \\
\text { findings }\end{array}$ \\
\hline $\begin{array}{l}\text { Critical thinking learning } \\
\text { transfer }\end{array}$ & $\begin{array}{l}\text { The level of the medical undergraduate's agreement on how they } \\
\text { transfer the acquired critical thinking knowledge and skills to different } \\
\text { contexts. The process was started with conceptualised the concepts } \\
\text { of critical thinking learning transfer. Then, identified situations or cues } \\
\text { that promote learning transfer, understood the deep structure of a } \\
\text { clinical problem that enable them to recognise the issues rapidly. After } \\
\text { that, they have to practice the learned critical thinking knowledge and } \\
\text { skills. Finally, they created strategies that help critical thinking learning } \\
\text { transfer. }\end{array}$
\end{tabular}

Category A: Different conceptualisation of critical thinking transfer concepts

Category B: Situations that allow the critical thinking transfer

Category C: Understanding and examining the deep structure of a problem

Category D: Rapid recognition of a problem

Category E: Deliberate practice

Category F: Learning strategies that promote critical thinking transfer
The level of the medical undergraduate's agreement towards their conceptualisation on the critical thinking transfer concepts.

The level of the medical undergraduate's agreement on different situations that allowed critical thinking learning transfer such as learning situation, personal situation, daily situation and non-learning situation.

The level of the medical undergraduate's agreement on their understanding of the deep structures of a clinical problem to perform critical thinking transfer. The deep structures of the problem were problem definition, etiology of disease, signs and symptoms, history of the past illness (s), pathophysiological mechanism, psychosocial factor investigation, treatment or intervention.

The level of the medical undergraduate's agreement on the attributes of rapid recognition of a clinical problem, factors promoting quick recognition of the problem and the process of immediate recognition of the problem.

The level of the medical undergraduate's agreement on how they deliberately practice their critical thinking learning by determining the aim of practice, the time for practice, the opportunity for practice and putting the awareness of practice critical thinking.

The level of the medical undergraduate's agreement on the strategies they used to transfer their critical thinking learning such as self-directed learning strategy, classroom learning strategy, experiential learning strategy and procedural learning strategy.
During the confirmation of the data, all participants were satisfied with the qualitative codes given to their feedbacks during the interview sessions. Based on the team members' evaluation, all the members mentioned gaps in the data of the first interview session. The informants' feedback were not enough resulted in certain categories existed. So, they agreed to ask the probing questions in the 2 nd interview session. Also, some of them agreed to re- arrange the interview questions. Questions should start with easy questions, such as questions related to students' experiences. Avoided stating with the hard questions such as questions about the critical thinking transfer concepts. After the 2nd interview, all the team members agreed that the theme, categories, sub-categories, codes and operational definitions were congruent with the research objective. Also, they agreed to build the construct, sub-constructs and 
attributes and their descriptions from the data (theme, categories, sub categories, codes and operational definitions).

Besides the team members' evaluation, the experts agreed that the data were relevant to medical undergraduates' CTTP, and the theme was concordance with the research objective (Cohen Kappa value $>0.80$ ). In the end, all categories (Category $\mathrm{A}$ to Category F) were maintained under the theme. Table 4 shows that the revised theme, categories and sub-categories. The revision resulted in constructing construct, sub-constructs and attributes that were relevant to medical undergraduates learning. Based on this revision, the blue arrow represented the formation of the final CTTP construct from the theme. The six categories formed the final six sub-constructs, while the sub-categories were used to develop the attributes relevant for medical undergraduates' learning.

Table 4: Development of CTTP constructs and sub-constructs specific for medical undergraduates' learning from the themes, categories and codes

\begin{tabular}{|c|c|c|c|c|}
\hline Themes & Construct & Categories & Sub-constructs & Sub-category/Attributes \\
\hline \multirow[t]{6}{*}{$\begin{array}{l}\text { Theme 2: } \\
\text { Critical thinking } \\
\text { learning } \\
\text { transfer } \\
\text { (revised) }\end{array}$} & \multirow[t]{6}{*}{$\begin{array}{l}\text { Construct 2: } \\
\text { Medical } \\
\text { undergraduates' } \\
\text { critical thinking } \\
\text { learning transfer }\end{array}$} & $\begin{array}{l}\text { A: Different } \\
\text { conceptualisation } \\
\text { of critical thinking } \\
\text { transfer concepts } \\
\text { (revised) }\end{array}$ & $\begin{array}{l}\text { A: } \\
\text { Conceptualising } \\
\text { critical thinking } \\
\text { transfer }\end{array}$ & \multirow{6}{*}{$\begin{array}{l}\text { Intra-subject transfer } \\
\text { Inter-subject transfer } \\
\text { Trans discipline transfer } \\
\text { Transfer to an entirely new } \\
\text { situation } \\
\text { Integrated transfer } \\
\text { Learning situation } \\
\text { Personal situation } \\
\text { Daily situation } \\
\text { Non-learning situation } \\
\text { Problem definition } \\
\text { Aetiology of disease } \\
\text { Signs and symptoms } \\
\text { History of past disease(s) } \\
\text { Pathophysiological mechanism } \\
\text { Psychosocial factor } \\
\text { Investigation } \\
\text { Treatment or intervention } \\
\text { Attributes of rapid recognition } \\
\text { of a problem } \\
\text { Factors promoting rapid } \\
\text { recognition of a problem } \\
\text { Process of rapid recognition of } \\
\text { a problem } \\
\text { Aim of practice } \\
\text { Practice time } \\
\text { Opportunity for practice } \\
\text { Awareness for practice } \\
\text { Self-directed learning strategy } \\
\text { Classroom learning strategy } \\
\text { Experiential learning strategy }\end{array}$} \\
\hline & & $\begin{array}{l}\text { B: Situations/cues } \\
\text { that allow the } \\
\text { critical thinking } \\
\text { transfer (revised) }\end{array}$ & $\begin{array}{l}\text { B: Determining } \\
\text { situations that } \\
\text { will enable the } \\
\text { critical thinking } \\
\text { transfer }\end{array}$ & \\
\hline & & $\begin{array}{l}\text { C: Understanding } \\
\text { and examining } \\
\text { the deep } \\
\text { structure of } \\
\text { a problem } \\
\text { (maintained) }\end{array}$ & $\begin{array}{l}\text { C: } \\
\text { Understanding } \\
\text { and examining } \\
\text { the deep } \\
\text { structure of a } \\
\text { problem }\end{array}$ & \\
\hline & & $\begin{array}{l}\text { D: Rapid } \\
\text { recognition of a } \\
\text { problem (revised) }\end{array}$ & $\begin{array}{l}\text { D: Recognising a } \\
\text { problem rapidly }\end{array}$ & \\
\hline & & $\begin{array}{l}\text { E: Deliberate } \\
\text { practice (revised) }\end{array}$ & $\begin{array}{l}\text { E: Practicing } \\
\text { critical thinking } \\
\text { deliberately }\end{array}$ & \\
\hline & & $\begin{array}{l}\text { F: Learning } \\
\text { strategies that } \\
\text { promote critical } \\
\text { thinking transfer } \\
\text { (revised) }\end{array}$ & $\begin{array}{l}\text { F: Developing } \\
\text { strategies } \\
\text { that promote } \\
\text { critical thinking } \\
\text { learning transfer }\end{array}$ & \\
\hline
\end{tabular}




\section{DISCUSSION}

The study successfully developed the construct and sub-constructs that specifically represented the CTTP among medical undergraduates. The study described how the prior construct and sub-constructs evolved from the concepts and process of critical thinking learning transfer for the general learning to the development of the CTTP construct and sub-constructs relevant for the medical undergraduates. The prior construct was initially conceptualised as the process of critical thinking learning transfer of the undergraduates in general learning (29, 47) based on the theories underlying this study $(4,10,22,31-44)$. The six prior subconstructs described the construct. The prior construct and sub-constructs were not initially related and relevant for the medical undergraduates' learning. Thus, a study framework was conceptualised to explain the theoretical relationship of the construct and sub-constructs. A qualitative study was also conducted to ensure that the construct and sub-constructs were relevant to the context of the medical undergraduates' learning.

In the study context, the construct and sub-constructs were found similar to the prior construct and sub-constructs. The similarity might be due to the participants in the general studies and their level of education, which was the undergraduates level. However, Illeris stated that learning in higher education could be changed by the manipulation of learning acquisition and student-environment interactions (51). Ennis also asserted on the subjectbased critical thinking that was related to the field of study (8). These arguments explained the new findings (attributes) reported in the study context. These new findings resulted in the reconceptualised of the construct and the prior sub-constructs (A to $\mathrm{F}$ ). The prior construct (a process of critical learning transfer of undergraduates) was reconceptualised to CTTP that were relevant for medical undergraduates.
The final sub-constructs were also reconceptualised based on the new findings (the attributes).

The prior sub-construct A was initially adopted from the concept of learning transfer of the learning transfer theory (34). Next, the study focused on the critical thinking transfer concept $(2,13-14)$. Two attributes of (near and far) transfer that emerged from the reviews were not contextual to the medical undergraduates' learning with no clear picture of how those attributes occurred in the study context. Thus, based on the study findings, five attributes of critical thinking learning transfer were conceptualised relevant to the medical undergraduates' learning, including the aforementioned attributes of transfer (near and far). However, in the study context, each attribute was described in detail of how far the transfer occurred in the context of medical undergraduates' learning. For example, near transfer from the theories was conceptualised as the transfer that occurred from a learning situation to the new learning situation, which was specified into three attributes, intra-subject transfer (a transfer that occurs from one medical component to another medical component in a medical subject), inter-subject transfer (a transfer that occurs between the medical subjects such as the skill of an organ analysis can be transferred from anatomy to pathology subjects), and trans-discipline transfer (a transfer that occurs between clinical disciplines or postings). Meanwhile, two attributes of far transfer were described as the transfer to an entirely new situation from a learning to a real-world context that was wholly different from the prior learning context, such as personal situation, professional situation and non-clinical event. Finally, the attribute of "integrated transfer, transfer that can occur to any situations" was conceptualised based on the idea of transfer from the critical thinking theorists $(10,52-53)$. The difference of "integrated transfer" in the study context was the transfer occurs in both clinical and non- 
clinical events. Based on the attributes, the prior sub-construct $\mathrm{A}$ was reconceptualised to the final sub-construct A (conceptualising the critical thinking learning transfer concept). The sub-construct was the main contributor to the CTTP construct as it was the fundamental of CTTP.

The prior sub-construct $\mathrm{B}$ was constructed based on the literature related to recognising keywords or signals from the learning environment that might trigger critical thinking transfer (39, 54-55). However, the reviews were limited to the learning situation that promoted critical thinking transfer in a non-medical context and did not detail what kinds of learning situations promoted the transfer. Thus, in the study context, the learning situations were detailed and contextualised to the medical undergraduates' learning. For example, classroom learning was detailed into learning critical thinking in the clinical workshops, clinical postings, tutorial classes, problem-based learning and case-based learning. Also, the study came out with another three situations that might help in critical thinking learning transfer in the context of medical undergraduates' learning. The situations were conceptualised as nonlearning situations; (a) personal situations such as dealing with issues of family, (b) daily situations such as the selection of nutritional foods in the cafeteria, and (c) non-clinical event like evaluating the debate of political issues. Besides, literature has described the cues recognition in the medical contexts such as verbal and nonverbal cues of patients or specific patterns developed in a clinical problem (56-58). Thus, another situation was conceptualised to promote the CTTP in the real-world situation such as situations occurred with real patients or real clinical problem in bed-side teaching and learning activities. The detail of the situations resulted in the reconceptualised of the prior sub-construct $\mathrm{B}$ to the final sub-construct $\mathrm{B}$ (recognising cues or situations that allow for critical thinking learning transfer).
Next, learning transfer theory (34) and the learning theorists $(8,59-62)$ have described the relationship between knowledge and critical thinking transfer. Based on the theories, the CTTP was conceptualised based on the learner's ability to determine the specific attributes of a learning situation. However, the theories did not describe the specific attributes in detail and the knowledge described by the theorists was general. Therefore, the past studies (13, 63) were reviewed to explore the details of the specific attributes aforementioned. Based on the studies, the specific attributes for practising critical thinking learning transfer were symptoms, psychosocial factors, and the clinical intervention. Thus, the sub-construct $\mathrm{C}$ was conceptualised with the details of attributes addressing the deep structure of the problem that help the medical undergraduates to transfer their critical thinking. Those attributes were the problem definition, aetiology, signs and symptoms, clinical history, pathophysiological mechanism of the disease and psychosocial factors that led to the disease progress, intervention and clinical investigation.

Another CTTP prior sub-construct D (rapid recognition of problem) was adopted from the literature of the pattern recognition concept (64-67). The literature contributed to the descriptions of the rapid recognition (quick, automatic, classical finding and effortless) that contextualise medical undergraduates' learning. However, the literature findings only contributed to one attribute (the descriptions of rapid recognition). Adding to the literature, this study found a new attribute of the factors promoting the rapid recognition of the problem. The factors determined were the past learning experiences, clinical-based learning experience, the complexity of the disease, the presentation of keywords and specific attributes of the problem. Besides, the process of rapid recognition of the problem from the literature (68-69) was fitted under sub-construct $\mathrm{D}$, resulting in the conceptualisation of steps to quickly 
recognise a clinical problem. The steps started from rapid recognition of the clinical problem until the decision made to address the problem. Thus, the attributes helped in reconceptualised of the prior sub-construct $\mathrm{D}$ and formed the final sub-construct $\mathrm{D}$ (recognising a clinical problem rapidly).

The prior sub-construct $\mathrm{E}$ was initially adopted from the literature on the concept of deliberate practice of critical thinking and theory of self-awareness for practising critical thinking (70-73). Based on the literature, the attributes of the goal for practice, time for practice, the opportunity for practice and self-awareness for practising critical thinking have emerged. However, the literature findings were not contextual to the medical undergraduates' learning. Thus, a qualitative study was conducted to formulate the attributes of the sub-construct specific to medical undergraduates' learning. The attributes were the aim of practice, practice time, the opportunity for practice and awareness to practice the critical thinking skills. Thus, these attributes resulted in conceptualisation of the final sub-construct $\mathrm{E}$ (practising critical thinking deliberately).

Finally, the prior sub-construct $\mathrm{F}$ was adopted from the literature on the concept of learning strategy. Based on the reviews, three learning strategies were found namely, surface learning strategy, deep learning strategy and pro-active learning strategy. The study has added value to the literature findings, in which the details of learning strategies were described, such as facts memorisation, journal evaluation, small group discussion and development of concept map. The study also formed new attributes such as classroom learning and experiential learning strategies. Based on these attributes, the prior sub-construct $\mathrm{F}$ was revised to "developing strategies that promote critical thinking learning transfer".

\section{CONCLUSION}

In summary, the CTTP concepts and processes emerged from the underlying theories and the general studies, which conceptualised the framework of this study. The framework described the theoretical relationship between the CTTP construct and six sub-constructs (A to F). However, those construct and sub-constructs were more contextual for the general learning. Thus, the qualitative study was conducted to ensure that the prior construct and subconstructs became more relevant to the medical undergraduates' learning context. Based on the qualitative findings, this study has given added value to the prior construct and sub-constructs regarding the descriptions of each sub-construct called the attributes. The attributes mostly derived from the qualitative codes of the study context, which helped to refine the prior construct and sub-constructs so that the final construct and sub-constructs were more relevant to medical undergraduates' learning. The final CTTP construct and sub-constructs were used for the development of the items in the CTTP instrument. The instrument was also tested for psychometric properties. The study concluded that the construct and sub-constructs were theoretically proven to represent the medical undergraduates' CTTP. The findings from this study add to the available information on CTTP in the medical education context conducted in Malaysia.

\section{ACKNOWLEDGEMENTS}

The authors gratefully acknowledge the support from the Faculty of Medicine, Universiti Kebangsaan Malaysia. This work was supported by the Sekretariat Penyelidikan Perubatan dan Inovasi, Universiti Kebangsaan Malaysia Medical Centre grant FF-2017-436. 


\section{REFERENCES}

1. Bruce R, Levett-Jones T, Courtney-Pratt H. Transfer of learning from university-based simulation experiences to nursing students' future clinical practice: an exploratory study. Clin Simul Nurs. 2019;35:17-24. https:// doi.org/10.5965/2175180306112014028

2. Christie B, Beames S, Higgins P. Context, culture and critical thinking: Scottish secondary school teachers' and pupils' experiences of outdoor learning. $\mathrm{Br}$ Educ Res J. 2016;42(3):417-37. https://doi. org/10.1002/berj.3213

3. Stanton MT, Guerin S, Barrett T. The transfer of problem-based learning skills to pro clinical practice. Interdiscip J Probl Learn. 2017;11(2). https://doi.org/10.1002/ berj. 3213

4. Tiruneh DT, Gu X, De Cock M, Elen J. Systematic design of domain-specific instruction on near and far transfer of critical thinking skills. Int J Educ Res. 2018;87:1-11. https://doi.org/10.1016/j. ijer.2017.10.005

5. Espey M. Enhancing critical thinking using team-based learning. High Educ Res Dev. 2018;37(1):15-29. https://doi.org/10.1080/0 7294360.2017 .1344196

6. Gharib M, Zolfaghari M, Mojtahedzadeh R, Mohammadi A, Gharib A. Promotion of critical thinking in e-learning: a qualitative study on the experiences of instructors and students. Adv Med Educ Pract. 2016;7:2719. https://doi.org/10.2147/AMEP.S105226

7. Turner K, Wattanakul B. Development of EREC IF model to increase critical thinking and creativity skills of undergraduate nursing students. Int J Soc Behav Educ Econ Bussiness, Ind Eng. 2016;5(6):1763-7. https://doi.org/10.5281/zenodo.1124731

8. Ennis RH. Critical thinking and subject specificity: clarification and needed research. Educ Res. 1989;18(3):4-10. https://doi. org/10.3102\%2F0013189X018003004
9. Glaser R. Education and thinking: the role of knowledge. Am Psychol. 1984;2(39):93104. https://doi.org/10.1037/0003066X.39.2.93

10. Halpern DF. Teaching critical thinking for transfer across domains. Am Psychol. 1998;53(4):449-55. https://doi. org/10.1037//0003-066x.53.4.449

11. Ghee LK, editor. The history of medicine and health in Malaysia. Selangor: Lim Kean Ghee; 2016. p.1-249.

12. Ismail R. Functional dependence and nutritional status. J Clin Heal Sci. 2017;2(Part 2):8-13.

13. Ennis RH. Critical thinking across the curriculum: a vision. Sci + Bussiness Media. 2016;(2011):1-20. https://doi.org/10.1007/ s1 1245-016-9401-4

14. Haskell RE. Transfer of learning cognition, instruction, and reasoning. Vol. 6. Biddeford, Maine: Academic Press; 2016. p.1-241.

15. Ismail NS, Harun J, Megat, Zakaria AZM, Salleh SM. The effect of mobile problembased learning application DicScience PBL on students' critical thinking. Think Ski Creat. 2018;S1871. https://doi. org/10.1016/j.tsc.2018.04.002

16. Umar Baki N, Rafik-Galea S, Nimehchisalem V. Malaysian rural ESL students' critical thinking literacy: a case study. Int J Educ Lit Stud. 2016;4(4). https://doi.org/10.7575/aiac.ijels.v.4n.4p.71.

17. Halpern DF. Thought \& knowledge: an introduction to critical thinking. 5th ed. New York: Psychology Press; 2014. p. 1-654.

18. Jerome C, Lee JAC, Ting SH. What students really need: instructional strategies that enhance higher order thinking skills (HOTS) among UNIMAS undergraduates. Int J Bus Soc. 2017;18(S4):661-8. 
19. Lim JW, Othman J, Lo YY. Implementing a discipline-specific reflective critical thinking module for literature in English in Malaysia. Innov Educ Teach Int. 2019;56(6):690-9. https://doi.org/10.1080/14703297.2019.156 7370

20. Roumell EA. Priming adult learners for learning transfer: beyond content and delivery. Adult Learn. 2019;30(1):15-22. https://doi.org/10.1177/1045159518791281

21. Tiruneh DT, Weldeslassie AG, Kassa A, Tefera Z, De Cock M, Elen J. Systematic design of a learning environment for domain-specific and domain-general critical thinking skills. Educ Technol Res Dev. 2016;64(3):481-505. https://doi. org/10.1007/s1 1423-015-9417-2

22. van Peppen LM, Verkoeijen PPJL, Heijltjes AEG, Janssen EM, Koopmans D, van Gog T. Effects of self-explaining on learning and transfer of critical thinking skills. Front Educ. 2018;3:1-11.

23. Sahoo S, Mohammed CA. Fostering critical thinking and collaborative learning skills among medical students through a research protocol writing activity in the curriculum. Korean J Med Educ. 2018;30(2):109-18. https://doi.org/10.3946/kjme.2018.86

24. Kilbrink N, Bjurulf V, Baartman LKJ, de Bruijn E. Transfer of learning in Swedish technical vocational education: student experiences in the energy and industry programmes. J Vocat Educ Train. 2018;70(3):455-75. https://doi.org/10.1080/ 13636820.2018 .1437064

25. Ludin SM. Does good critical thinking equal effective decision-making among critical care nurses? A cross-sectional survey. Intensive Crit Care Nurs. 2018;44:1-10. https://doi. org/10.1016/j.iccn.2017.06.002
26. Raaijmakers SF, Baars M, Paas F, van Merriënboer JJG, van Gog T. Training selfassessment and task-selection skills to foster self-regulated learning: do trained skills transfer across domains? Appl Cogn Psychol. 2018;32(2):270-7. https://doi.org/10.1002/ acp.3392

27. Wang C, Zhang X, Yao M. Enhancing Chinese college students' transfer of learning through service-learning. Stud High Educ. 2018;1-16. https://doi.org/10.1080/0307507 9.2018.1435635

28. Zabit MNM, Karagiannidou E, Zacharia TZ. Teaching business in Malaysia and the use of PBL to nurture students' critical thinking: a case study of Sultan Idris Education University. Geogr - Malaysian J Soc Sp. 2016;12(6):1-11.

29. Merriam SB, Tisdell EJ. Qualitative research a guide to design and implementation. 4th ed. San Fracisco: A Wiley Brand; 2016. p.1346.

30. Sutton J, Austin Z. Qualitative research: data collection, analysis, and management. Can J Hosp Pharm. 2015;68(3):226-31.

31. Axeldrod R. Schema theory: an information processing model of perception and cognition. Am Polit Sci Rev. 1973;67:124866. https://doi.org/10.2307/1956546

32. Sweller J. Cognitive load during problem solving: effects on learning. Cogn Sci. 1988;12(2):257-85. https://doi. org/10.1016/0364-0213(88)90023-7

33. Khalil MK, Elkhider IA. Applying learning theories and instructional design models for effective instruction. Adv Physiol Educ. 2016;40(2):147-56.

34. Perkins DN, Salomon G. Transfer of learning. In: McGaw B, Peterson P, Baker EL, editors. International encyclopedia of education. 2nd ed. UK: Pergamon Press; 1992. p. 1-13. 
35. Horn S, Veermans K. Critical thinking efficacy and transfer skills defend against 'fake news' at an international school in Finland. J Res Int Educ. 2019;18(1):23-41. https://doi.org/10.1177/1475240919830003

36. Crawford T, Roger P, Candlin S. Supporting patient education using schema theory: a discourseanalysis. Collegian. 2018;25(5):501-7. https://doi.org/10.1016/j. colegn.2017.12.004

37. Mancinetti M, Guttormsenb S, Berendonkb C. Cognitive load in internal medicine: what every clinical teacher should know about cognitive load theory. Eur J Intern Med. 2018;1-5. https://doi.org/10.1016/j. ejim.2018.08.013.

38. Leppink J. Cognitive load theory: practical implications and an important challenge. J Taibah Univ Med Sci. 2017;12(5):385-91. https://doi.org/10.1016/j.jtumed.2017.05.003

39. Anique B, Bruin D, Sibbald M, Monteiro S. The science of learning. In: Swanwick T, Forest K, O'Brien BC, editors. Medical Education Evidence, Theory, and Practice. 3rd ed. Oxford, UK: Wiley Blackwell; 2019. p. $1-580$.

40. Robin J, Garzon L, Moscovitch M. Spontaneous memory retrieval varies based on familiarity with a spatial context. Cognition. 2019;190:81-92. https://doi. org/10.1016/j.cognition.2019.04.018

41. Sunde KE, Cutsforth-Gregory JK, Hunderfund ANL. The basic four approach to clinical neuroscience instruction: using cognitive load theory to enhance case-based learning. J Med Educ Curric Dev. 2018;5:16. https://doi.org/10.1177/23821205188156

42. Kok EM, Geel K van, Merrienboer JJ van, Roben SG. What we do and do not know about teaching medical image interpretation. Front Psychol. 2017;8(309):1-8. https://doi. org/10.3389/fpsyg.2017.00309
43. ten Cate O, Custers EJFM, Durning SJ. In: Gijselaers WH, editor. Principles and practice of case-based clinical reasoning education a method for preclinical students. 15th ed. Netherlands: Springer; 2017.

44. Schmidt HG, Mamede S. How cognitive psychology changed the face of medical education research. Adv Heal Sci Educ. 2020;25:1025-43. https://doi.org/10.1007/ s 10459-020-10011-0

45. Jespersen LN, Michelsen SI, Holstein BE, Tjornhoj-Thomsen $\mathrm{T}$, Due P. Conceptualization, operationalization, and content validity of the EQOL-questionnaire measuring quality of life and participation for persons with disabilities. Health Qual Life Outcomes. 2018;16(199):1-16. https:// doi.org/10.1186/s12955-018-1024-6

46. Waltz CF, Strickland OL, Land ER. Measurement in nursing and health research. 4th ed. New York: Springer Publishing Company; 2010.

47. Creswell JW, Poth CN. Qualitative inquiry and research design choosing among five approaches. 4th ed. California: SAGE Publications LTD; 2018. p.1-459.

48. Cohen J. A coefficient of agreement for nominal scales. Educ Psychol Meas. 1960;20(1):37-46.

49. Ghazali HD, Hussin S. Metodologi penyelidikan dalam pendidikan amalan dan analisis kajian. 2th ed. Kuala Lumpur, Malaysia: Penerbit Universiti Malaya; 2016. p. 1-574.

50. Landis JR, Koch GG. The measurement of observer agreement for categorical data. Biometrics. 1977;33(1):159. https://doi. org $/ 10.2307 / 2529310$

51. Illeris $\mathrm{K}$, editor. Comprehensive understanding of human learning. In: Contemporary theories of learning. UK: Routledge; 2018. p.7-20. 
52. Kuhn D. A developmental model of critical thinking. Educ Res. 1999;28(2):16-25. https://doi.org/10.2307/1177186

53. Paul R. Critical thinking: what, why, and how. New Directions for Community Colleges. 1992;77:3-24. https://doi. org/10.1002/cc.36819927703

54. Procaccini SJ, Carlino NJ, Joseph DM. Clinical teaching methods for stimulating students' critical thinking. Perspect ASHA Spec Interes Groups. 2016;1(11):3.

55. Tiruneh DT, Cock $M$ De. Designing learning environments for critical thinking: examining effective instructional approaches. Int J Sci Math Educ. 2017;16:1065-9. https://doi.org/10.1007/s10763-017-9829-z

56. $\mathrm{Fu}$ B. Common ground: Frameworks for teaching improvisational ability in medical education. Teach Learn Med. 2018;1-14. https://doi.org/10.1080/10401334.2018.153 7880

57. Giroldia E, Timmermana A, Veldhuijzena W, Murisa J, Vleuten C van der, Weijdena $\mathrm{T}$ van der. How doctors recognise that their patients are worried: a qualitative study of patient cues. Patient Educ Couns. 2019;1-6. https://doi.org/10.1016/j.pec.2019.09.023

58. Krishnan P. A philosophical analysis of clinical decision making in nursing. J Nurs Educ. 2018;57(2):73-8. https://doi. org/10.3928/01484834-20180123-03

59. Billing D. Teaching for transfer of core/ key skills in higher education: cognitive skills. Higher Education. 2007;53:483-516. https://doi.org/10.1007/s10734-005-5628-5

60. Brell CD. Critical thinking as transfer: the reconstructive integration of otherwise discrete interpretations of experience. Educ Theory. 1990;40(1):53-68. https://doi. org/10.1111/j.1741-5446.1990.00053.x

61. Geertsen R. Barriers to critical thinking across domains. Rev Manage Inn \& Creat. 2013;6(20):52-60.
62. Peck JEM. Critical thinking and subject specificity: a reply to Ennis. Educ Res. 1990;19(4):10-4. https://doi. org/10.3102/0013189X019004010

63. Cargas S. Honoring controversy: using realworld problems to teach critical thinking in honors courses. Honor Pract. 2016;12:12337.

64. Ling MKD, Loh SC. Relationship of creativity and critical thinking to pattern recognition among Singapore private school students. J Educ Res. 2020;1-17. https://doi. org/10.1080/00220671.2020.1716203

65. Ling MKD. Applications of science of learning principles to support teaching and learning of cognitive pattern recognition. Tech Soc Sci J. 2021;16:62-76.

66. Manetti W. Sound clinical judgment in nursing: a concept analysis. Nurs Forum. 2018;1-9. https://doi.org/10.1111/nuf.12303

67. Schmehl PK. Clinical judgment and cue recognition of patient deterioration among novice nurses [dissertation]. Grand Canyon University; 2019.

68. Hayes MM, Chatterjee S, Schwartzstein RM. Seminars for medical educators. In: Critical thinking in critical care: Five strategies to improve teaching and learning in the intensive care unit. Ann Am Thorac Soc. 2017;14(4):569-75. https://doi. org/10.1513/AnnalsATS.201612-1009AS.

69. Zhang BXY, Liu CL, Suen CY. Towards robust pattern recognition: a review. Proceedings of the IEEE. 2020;108(6): 894-922. https://doi.org/10.1109/ JPROC.2020.2989782

70. Hakelind C, Steinvall A, Deutschmann M. The power of aha! On stimulating and guiding students towards selfawareness and critical reflection while teaching about personality psychology and gender stereotypes. Psychol Learn Teach. 2020;1-16. https:/doi. org/10.1177/1475725720979460 
71. Heydarnejad T, Fatemi AH, Ghonsooly B. The relationship between critical thinking, self-regulation, and teaching style preferences among EFL teachers: a path analysis approach. J Lang Educ. 2021;7(1):96-108. https://doi.org/10.17323/ jle.2021.11103

72. Smith EM, Holmes NG. Evaluating instructional labs' use of deliberate practice to teach critical thinking skills. Phys Rev Phys Educ Res. 2020;16(2):1-17. https://doi.org/10.1103/ PhysRevPhysEducRes.16.020150
73. Wang XM, Hwang GJ, Liang ZY, Wang HY. Enhancing students' computer programming performances, critical thinking awareness and attitudes towards programming: an online peer-assessment attempt. Int Forum Educ Technol Soc. 2017;20(4):58-68. 